\title{
Synthesis and Characterization of a New Microporous Cesium Silicotitanate (SNL-B) Molecular Sieve.
}

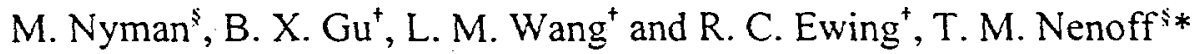 \\ \$Sandia National Laboratories, Catalysis and Chemical Technologies; P.O. Box 5800, \\ M.S. 0710; Albuquerque, NM 87185-0710. \\ ${ }^{+}$University of Michigan, Department of Nuclear Engineering and Radiological Sciences; \\ Ann Arbor, MI 48109-2104.
}

*Author to whom correspondence should be addressed (email: tmnenof@sandia.gov).

Ongoing hydrothermal Cs-Ti-Si- $\mathrm{O}-\mathrm{H}_{2} \mathrm{O}$ phase investigations has produced several new
with the approximate formula of $\mathrm{Cs}_{3} \mathrm{TiSi}_{3} \mathrm{O}_{9.5} \cdot 3 \mathrm{H}_{2} \mathrm{O}$. SNL-B is only the second molecular sieve Cs-silicotitanate phase reported to have been synthesized by hydrothermal methods. Crystallites are very small $(0.1 \times 2$ microns $)$ with a blade-like morphology. SNL-B is confirmed to be a 3-dimensional molecular sieve by a variety of characterization techniques $\left(\mathrm{N}_{2}\right.$ adsorption, ion exchange, water adsorption/desorption, solid state CP-MAS NMR). SNL-B is able to desorb and adsorb water from its pores while retaining its crystal structure and exchanges Cs cations readily. Additional techniques were used to describe fundamental properties (powder X-ray diffraction, FTIR, ${ }^{29} \mathrm{Si}$ and ${ }^{133} \mathrm{Cs}$ MAS NMR, DTA, SEM/EDS, ion selectivity, and radiation stability). The phase relationships of metastable SNL-B to other hydrothermally synthesized Cs-Ti-Si-O- $\mathrm{H}_{2} \mathrm{O}$ phases are discussed, particularly its relationship to a Cs-silicotitanate analogue of phamacosiderite, and a novel condensed phase, a polymorph of $\mathrm{CS}_{2} \mathrm{TiSi}_{6} \mathrm{O}_{15}(\mathrm{SNL}-\mathrm{A})$.

Kelwords: molecular sieve, silicotitanates, $\mathrm{Cs}$ and $\mathrm{Sr}$ radionuclides, electron beam irradiation. 


\section{DISCLAIMER}

This report was prepared as an account of work sponsored by an agency of the United States Government. Neither the United States Government nor any agency thereof, nor any of their employees, make any warranty, express or implied, or assumes any legal liability or responsibility for the accuracy, completeness, or usefulness of any information, apparatus, product, or process disclosed, or represents that its use would not infringe privately owned rights. Reference herein to any specific commercial product, process, or service by trade name, trademark, manufacturer, or otherwise does not necessarily constitute or imply its endorsement, recommendation, or favoring by the United States Government or any agency thereof. The views and opinions of authors expressed herein do not necessarily state or reflect those of the United States Government or any agency thereof. 


\section{DISCLAIMER}

Portions of this document may be illegible in electronic image products. Images are produced from the best available original document. 


\section{Introduction}

The CST ion exchanger, a crystalline silicotitanate material jointly developed by Sandia National Laboratories (SNL) and Texas A \& M University, is highly selective for Cs over a broad $\mathrm{pH}$ range and in the presence of competitive ions (i.e. Na).[1-5] Additionally, it is stable in extreme radioactive and chemical environments.[4] These properties make the CST ion exchanger useful for removal of the ${ }^{137} \mathrm{Cs}$ radionuclide from defense wastes such as those stored at the Hanford site. However, the Cs-loaded CST is not easily backexchanged without destroying the framework structure.[4] Therefore, the CST material must be incorporated into a waste form for immobilization of ${ }^{137} \mathrm{Cs}$ that has been selectively sorbed. Direct thermal conversion of the Cs-CST produces a viable waste form by dehydration and phase transformation to form a mixture of crystalline products. $[6,7]$ In order to fully characterize the phases which 1) compose the original waste form material, and 2) precipitate as secondary alteration phases, exploratory syntheses are underway using the component oxides of Cs-CST. In particular, synthesis of Cs-Ti-Si-O- $\mathrm{H}_{2} \mathrm{O}$ ternary phases directed toward Cs-CST waste form characterization is the current focus of the ongoing studies.

In addition to supplementing Cs-CST waste form characterization [6,7], ongoing hydrothermal synthesis experiments in the system Cs- $\mathrm{Ti}-\mathrm{Si}-\mathrm{O}-\mathrm{H}_{2} \mathrm{O}$ have led to the identification of new materials [8-10]. Herein, we report a novel Cs-silicotitanate ion exchanger phase named SNL-B, with the approximate formula of $\mathrm{Cs}_{3} \mathrm{TiSi}_{3} \mathrm{O}_{9.5} \cdot 3 \mathrm{H}_{2} \mathrm{O}$. SNL-B is the second reported ion exchanger Cs-silicotitanate phase, the first being an analogue to the mineral pharmacosiderite $\left(\mathrm{HCs}_{3} \mathrm{Ti}_{4} \mathrm{Si}_{3} \mathrm{O}_{16} \cdot 4 \mathrm{H}_{2} \mathrm{O}\right)$ [11-13] [Cs/Si/Tipharmacosiderite]. In fact, the only other previously reported Cs-Si-Ti-O ternary phases are $\mathrm{CsTiSi}_{2} \mathrm{O}_{6,5}$ (pollucite) and $\mathrm{Cs}_{2} \mathrm{TiSi}_{6} \mathrm{O}_{15}$, both of which are condensed tectosilicate phases in which $\mathrm{Cs}$ is not exchangeable. These phases were synthesized at PNNL by high temperature, solid-state techniques. $[9,10,14,15]$ More recently, a polymorph of $\mathrm{Cs}_{2} \mathrm{TiSi}_{n} \mathrm{O}_{15}$ has been produced by hydrothermal techniques at $\mathrm{SNL}$, designated SNL-A.[8, 16] 
Recent research in the silicotitanate field in the interest of new materials for catalysis and ion exchange has led to numerous new phases. These materials consist of framework tetrahedral silicon atoms, framework 4- 5- or 6- coordinate titanium atoms, interstitial or interlayer exchangeable cations, and removable water molecules. Some examples of silicotitanates include Ti- $\beta$ [17] and TS-1 [18], TS-2 [19], Ti-ZSM-48 [20], Timordenite[17, 21], ETS-4 [22, 23], ETS-10 [24, 25], a Na silicotitanate analogue of the mineral zorite [26], AM-4 [27], lintisite (naturally-occurring) [28], layered $\mathrm{Na}_{2} \mathrm{TiSi}_{2} \mathrm{O}_{7}$ - $2 \mathrm{H}_{2} \mathrm{O}$ [29], a sodium silicotitanate analogue of the mineral penkvilksite [30], nafertisite (naturally-occurring) [31], a Cs silicotitanate analogue to pharmacosiderite [11-13], CST (crystalline silicotitanate) [1-5] and JDF-L1 [32,33]. Reported information on these phases has greatly aided in the research into the Cs-Ti-Si-O- $\mathrm{H}_{2} \mathrm{O}$ phases.

The exploratory hydrothermal syntheses of Cs- $\mathrm{Ti}-\mathrm{Si}-\mathrm{O}-\mathrm{H}_{2} \mathrm{O}$ phases carried out at SNL are focused on phase identification, phase stability and interphase relationships, based on synthesis parameters including $\mathrm{Cs}_{2} \mathrm{O}: \mathrm{SiO}_{2}: \mathrm{TiO}_{2}$ precursor ratios, $\mathrm{pH}$, temperature and precursor solution concentration. New Cs-Ti-Si-O- $\mathrm{H}_{2} \mathrm{O}$ phases obtained from this study are characterized thoroughly with a focus on properties which affect $\mathrm{Cs}$ adsorption/desorption. Phase characterization techniques include powder X-ray diffraction, surface area analysis, FTIR, solid-state ${ }^{133} \mathrm{Cs}$ and ${ }^{29} \mathrm{Si}$ MAS NMR, thermal analyses, SEM/EDS, and electron beam irradiation. Additionally, ongoing calorimetric studies with Navrotsky et al., are providing information on thermodynamic stability of both the new phases and their ion exchanged derivatives.[34] 


\section{Experimental}

Synthesis of SNL-B. Titanium isopropoxide (TIPT) and tetraethylorthosilicate (TEOS), were combined and added dropwise to a mixture containing $50 \% \mathrm{CsOH}$ solution and amorphous $\mathrm{TiO}_{2}$ in a $23 \mathrm{ml}$ Tefion liner for a Parr pressure reactor. After stirring for 30 minutes, $\mathrm{H}_{2} \mathrm{O}$ was added and the mixture was stirred for 30 minutes more. The final $\mathrm{pH}$ of the mixture is 12.5 . The final reactant stoichiometry is $\mathrm{Cs}: \mathrm{Ti}: \mathrm{Si}: \mathrm{H}_{2} \mathrm{O}=4: 1: 4: 383$. The amorphous $\mathrm{TiO}_{2}$ is $1-10$ atomic $\%$ of the total titanium content of the precursor mixture. The loaded pressure reactor was placed in a $120^{\circ} \mathrm{C}$ oven for 14 days. The product was collected by filtration and washed with hot water.

Ion Exchange Experiments. Selectivity experiments for sodium and strontium were performed by combining $0.1 \mathrm{~g}$ ion exchanger (SNL-B) with $10 \mathrm{~g}$ of $50 \mathrm{ppm}$ metal nitrate $\left(\mathrm{NaNO}_{3}, \mathrm{Sr}\left(\mathrm{NO}_{3}\right)_{2}\right)$ solution. The ion exchanger was shaken with the solution overnight at $300 \mathrm{rpm}$. The solution was filtered and analyzed for sodium or strontium concentration by atomic adsorption spectroscopy (AAS). The distribution coefficients $\left(\mathrm{K}_{\mathrm{d}}\right)$ were calculated in $\mathrm{ml} / \mathrm{g}$ where $\mathrm{K}_{\mathrm{d}}$ is defined as:

$$
\mathrm{K}_{\mathrm{d}}=\left[\mathrm{M}_{\mathrm{IE}} / \mathrm{g} \mathrm{IE}\right] /\left[\mathrm{M}_{\mathrm{sln}} / \mathrm{ml} \sin \right]
$$

where $\mathrm{M}_{\mathrm{IE}}$ is concentration of the metal for exchange ( $\mathrm{Na}$ or $\mathrm{Sr}$ ) in ppm which is adsorbed onto the ion exchanger (IE), " $\mathrm{g}$ IE" is weight of the ion exchanger (SNL-B) in grams, $M_{\text {sin }}$ is concentration of the metal for ion exchange in $\mathrm{ppm}$ which remains in solution after contact with SNL-B, and "ml sln" is volume of the solution for ion exchange in milliliters. For maximum loading experiments, the ion exchanger was stirred overnight at $70{ }^{\circ} \mathrm{C}$ in a 100-fold excess, 1 molar solution of a metal salt of the exchange ion $\left(\mathrm{Sr}\left(\mathrm{NO}_{3}\right)_{2}\right.$ or $\left.\mathrm{NaNO}_{3}\right)$. The ion exchanged product was collected by vacuum filtration and thoroughly washed with hot water to remove excess salt. The percent of exchange was determined by AAS, and the ion exchange step was repeated until maximum loading was achieved. 
General Instrumentation and Characterization Techniques. The powder $X$-ray diffraction data (XRD) were collected on a Siemens D500 instrument using $\mathrm{Cu} \mathrm{K}_{\alpha}$ radiation between $2 \theta=5$ and $60^{\circ}$, a step size of $0.05^{\circ}$ and step time of 5 seconds. The powder pattern was indexed for unit cell determination using DICVOL91 software[35]. The ${ }^{29}$ Si MAS NMR (Magic Angle Spinning Nuclear Magnetic Resonance) spectra were obtained on a Bruker ASX300 at $59.6 \mathrm{MHz}$ using direct single pulse acquisition with 120 second recycle delay, 256 - 512 scans, spinning at $4 \mathrm{kHz}$, with $\mathrm{Q}_{8} \mathrm{M}_{8}(12.4 \mathrm{ppm})$ as an external reference. The ${ }^{29} \mathrm{Si}$ CP (cross polarization) MAS NMR spectra were recorded with a 5 millisecond contact time and 10 second recycle delay, and 128 to 256 scans. The ${ }^{13.3}$ Cs MAS NMR were recorded on an AMX400 at $52.49 \mathrm{MHz}$ using direct single pulse excitation with 10 second recycle delay, $2 \mu$ s pulse, 512 scans, spinning at $12.5 \mathrm{KHz}$, with $0.5 \mathrm{M} \mathrm{CsCl}$ solution $(0.00 \mathrm{ppm})$ as an external standard. The $\mathrm{CP}{ }^{13.3} \mathrm{Cs}$ experiments were obtained using contact times varying between $1-6 \mathrm{~ms}, 1 \mathrm{~s}$ recycle delay for ${ }^{1} \mathrm{H}$, and 1024 scans. Elemental analysis for $\mathrm{Cs}, \mathrm{Na}$ and $\mathrm{Sr}$ by atomic adsorption spectroscopy was performed on a Perkin Elmer 5100 PC AAS instrument. Solutions and standards were prepared with $1000 \mathrm{ppm}$ ionization suppressant. An acetylene/air flame was used for $\mathrm{Na}$ and $\mathrm{Cs}$ analyses and an acetylene/nitrous oxide flame was used for $\mathrm{Sr}$ analysis. The DTATGA experiments were performed on a STD 2960 TA DTA-TGA instrument with alumina as a standard for DTA. Samples $(10-15 \mathrm{mg})$ were heated in air. To obtain the water desorption/readsorption curves, a sample of SNL-B was heated at $10^{\circ} \mathrm{C} / \mathrm{min}$ up to $500^{\circ}$, cooled to $30^{\circ}$ at $1^{\circ} \mathrm{C} / \mathrm{min}$, and held for 200 minutes. Scanning electron microscopy (SEM) data was collected on a JEOL JSM-T300 SEM with energy dispersive capabilities. Transmission Electron Microscopy (TEM) data was collected on a JEM 2000FX TEM at University of Michigan. Infrared data (FTIR) was obtained from pressed pellet samples containing $1-3 \mathrm{wt} \%$ sample in a $\mathrm{KBr}$ matrix, analyzed on a Perkin Elmer Spectrum GX. Surface areas were determined using a Quantachrome Autosorb with nitrogen as the adsorbant. Samples were outgassed under vacuum at 100 ${ }^{\circ} \mathrm{C}$. Qualitative determination of microporosity was made via inspection of isotherms over the relative pressure range of $10^{-5}$ and $10^{\circ}$ and qualitative evaluation made using Deboer analysis of t-plots. 
Leach Tests. The standard PCT (product consistency test) leach test, a common technique developed to evaluate chemical durability of nuclear waste forms in aqueous environments[36, 37], was performed on SNL-B. A sample of the material $(0.2 \mathrm{~g})$ was placed in a hydrothermal reaction vessel with 10 grams of water at $90^{\circ} \mathrm{C}$ for $1,2,3,7$, and 10 days. After the designated time of heating, each sample was filtered, and the leachate solution was analyzed for Cs concentration by AAS. The solid product was analyzed by $\mathrm{XRD}$ to determine if any phase changes occurred as a result of the leach test. Surface area of samples for leach rate calculations were measured, as described above.

Electron Irradiation Studies. Electron irradiation studies of SNL-B were conducted with a JEM 2000FX transmission electron microscope at the University of Michigan. The electron energy used was $200 \mathrm{keV}$ and the sample was irradiated at a dose rate of $\sim 10^{18}$ electrons $/ \mathrm{s} \cdot \mathrm{cm}^{2}$. Temperature dependence of amorphization dose was studied over the range of $20-700^{\circ} \mathrm{C}$ by using hot stage capabilities of the TEM.

\section{Results and Discussion}

Synthesis of SNL-B. The synthesis method described above results in a typical crystallite size of $0.1 \times 2 \mu \mathrm{m}$. Procedure requires addition of small amounts of $\mathrm{TiO}_{2}$ to form the silicotitanate molecular sieve; exclusion produces only $\mathrm{Cs} / \mathrm{Si} / \mathrm{Ti}$-pharmacosiderite. All samples contain approximately 10 volume $\%$ of a known impurity phase $[\mathrm{Cs} / \mathrm{Si} / \mathrm{T} i$ pharmacosiderite]. However, the major phase of all samples is SNL-B (90\%) as confirmed by XRD, SEM/EDS and TGA. Consequently, bulk analyses were carried out with caution and consideration of the impurity phases. SNL-B is classified as a microporous molecular sieve based on both ion exchange behaviors and characterization results, including ion exchange capability, reversible hydration/dehydration of internal water molecules, irradiation response, and other spectroscopic characterizations discussed below.

Characterization of SNL-B. Through SEM-EDS and TGA, the formula of SNL-B has been determined to be $\mathrm{Cs}_{3} \mathrm{TiSi}_{3} \mathrm{O}_{9.5} \cdot 3 \mathrm{H}_{2} \mathrm{O}$. Other techniques for characterization include 
XRD, surface area analysis, FTIR, and solid state ${ }^{29} \mathrm{Si}$ and ${ }^{133} \mathrm{Cs}$ MAS NMR. The results of these characterizations are discussed below.

The Powder X-ray diffraction pattern of SNL-B is shown in figure 1. A thorough search of the JCPDS data base [38] by comparing the three most intense peaks did not provide a match for SNL-B to any known phase. Additionally, a literature search of silicate, aluminosilicate and silicotitanate phases did not provide a structural analogue to this phase. This phase was indexed as an orthorhombic system with cell parameters $a=10.83$ $\AA, b=7.43 \AA$ and $c=7.11 \AA$. The major observed and calculated peaks are listed in Table I. Crystallites of SNL-B were observed by SEM, as shown in figure 2. The crystals exhibit a blade-like habit, $\sim 0.1 \times 2 \mu \mathrm{m}$ in size, and the crystals grow in radiating aggregates. Due to the extremely small size of these crystallites, single crystal XRD structure determination has not yet proven successful.

The formula of SNL-B was determined by careful $E D S-S E M$ analysis on single crystals for Cs:Ti:Si ratios, and the water content was determined by thermogravimetric analysis. Bulk elemental analysis using atomic emission and adsorption techniques to determine composition were not utilized, due to the presence of the known impurity phase. Rather, multiple (20) EDS analyses were carried out on single crystals of SNL-B. Known $\mathrm{Cs} / \mathrm{Si} / \mathrm{Ti}$ phases, $\mathrm{Cs}_{2} \mathrm{TiSi}_{6} \mathrm{O}_{15}[16]$ and $\mathrm{Cs} / \mathrm{Si} / \mathrm{Ti}$ pharmacosiderite [11], were used as standards for the EDS analysis. The Cs:Ti:Si ratio of SNL-B determined by this technique is $3: 1: 3$.

Thermogravimetric data was obtained on a sample, which (figure 3) gave SNL-B a 7.5 weight $\%$ volatile component (water) which is consistent with the formula $\mathrm{Cs}_{3} \mathrm{TiSi}_{3} \mathrm{O}_{9.5} \cdot 3 \mathrm{H}_{2} \mathrm{O}$. The data on $\mathrm{SNL}-\mathrm{B}$ was obtained by initially removing the hydrous content of the $\mathrm{Cs} / \mathrm{Si} / \mathrm{Ti}$ pharmacosiderite impurity phase by heating. Cs/Si/Ti pharmacosiderite undergoes irreversible dehydration and structure collapse by $400^{\circ} \mathrm{C}$, whereas SNL-B exhibits thermal stability upon removal of water and up to $500^{\circ} \mathrm{C}$. The impurity content was confirmed to be $\sim 10 \%$ by observation of the percentage of irreversible water loss by TGA of the mixed sample. The remaining sample (SNL-B) was 
rehydrolyzed and analyzed for water content. The water is volatilized between $100-200$ ${ }^{\circ} \mathrm{C}$, and does not result in any structural change in SNL-B. Furthermore, the water is completely readsorbed upon slow cooling, as observed in figure 3 . Therefore, the water content is present as occluded $\mathrm{H}_{2} \mathrm{O}$ molecules rather than hydroxyl anions.

Pore surface area of SNL-B was studied by nitrogen adsorption. A pure, sample of the 3D molecular sieve $\mathrm{Cs} / \mathrm{Si} / \mathrm{Ti}$ pharmacosiderite was also analyzed for comparison (contains Cs cations and water molecules within channels). The isotherms for both samples displayed significant adsorption at low relative pressures, qualitatively indicating the presence of micropores. Total surface area calculated for SNL-B and $\mathrm{Cs} / \mathrm{Si} / \mathrm{Ti}$ pharmacosiderite are similar; $89 \mathrm{~m}^{2} / \mathrm{g}$ and $86 \mathrm{~m}^{2} / \mathrm{g}$, respectively. The apparent low BETdetermined surface areas of SNL-B and Cs/Si/Ti-pharmacosiderite (with $5 \AA$ pores, based on crystallographic data [13]) are likely a result of $\mathrm{Cs}$ and $\mathrm{H}_{2} \mathrm{O}$ within the microporous void space which hinder accessibility. Therefore, the majority of the quantified porosity is actually external surface area. [However, the combination of experimental results indicate that SNL-B has microporosity. Further indication of microporosity is seen in the ion exchange behavior of SNL-B, which is discussed later.]

FTIR: The mid-IR spectrum of SNL-B is shown in figure 4. The spectrum has peaks in three distinct regions; $400-750 \mathrm{~cm}^{-1}(\mathrm{I}), 850-1200 \mathrm{~cm}^{-1}$ (II), and $2800-3500 \mathrm{~cm}^{-1}$ (III). The lower frequency region I corresponds with Si-O-Ti vibrational modes and the Si-O-Si bending modes. $[33,39,40]$ The higher frequency region II corresponds with Si-O-Si stretching modes.[40] The large broad peak centered at $3500 \mathrm{~cm}^{-1}$ (region III) is assigned as $\mathrm{O}-\mathrm{H}$ stretching modes.

Solid-state ${ }^{29}$ Si and ${ }^{133}$ Cs MAS NMR and CP spectroscopies provide insight into the bonding environments of framework and interstitial atoms of SNL-B. The ${ }^{29} \mathrm{Si}$ and ${ }^{173} \mathrm{Cs}$ spectra are shown in figures $5 \mathrm{a}$ and $5 \mathrm{~b}$, respectively.

The ${ }^{29} \mathrm{Si}$ MAS NMIR chemical shifts are consistent with other reported $\mathrm{SiO}_{4}$ tetrahedral shifts for silicotitanates.[41-43] The ${ }^{29} \mathrm{Si}$ chemical shifts are assigned $\mathrm{Q}^{\mathrm{x}}$ designations, for 
which $\mathrm{x}$ is the number of $\mathrm{Si}$ in the second coordination sphere of the silicon tetrahedron, and $4-\mathrm{x}$ is the number of non-silicon atoms (Ti). The peak at $-87 \mathrm{ppm}$ is the $\mathrm{Cs} / \mathrm{Si} / \mathrm{Ti}$ pharmacosiderite impurity phase. The broadness of this peak in conjunction with the broad peaks observed in the diffraction pattern indicate poor crystallinity. By comparing the two remaining peaks of SNL-B to those of structurally characterized silicotitanates, the following assignments are made: $-97 \mathrm{ppm}$ is a $\mathrm{Q}^{2}$ or $\mathrm{Q}^{3}$ peak and $-105 \mathrm{ppm}$ is a $\mathrm{Q}^{3}$ or $\mathrm{Q}^{4}$ peak. The corollary cross polarization (CP) experiments gave only the peak at $-97 \mathrm{ppm}$ which suggests this silicon site is in closer proximity to the internal $\mathrm{H}_{2} \mathrm{O}$.

The ${ }^{133}$ Cs MAS NMR spectrum shows that SNL-B has two unique exchange sites occupied by Cs. The peak at $57 \mathrm{ppm}$ is the Cs/Si/Ti pharmacosiderite impurity phase. The corollary ${ }^{133} \mathrm{Cs} \mathrm{CP}-\mathrm{MAS}$ experiment gave the peak at $8 \mathrm{ppm}$, which suggests the Cs in this site is more hydrated than the $C s$ in the second site $(23 \mathrm{ppm})$. The resolution of the peaks at room temperature suggests that there is no rapid exchange between the Cs sites, as is reported for some Cs containing zeolites.[44] Upfield shifts of Cs peaks in general correspond with "less shielding".[44, 45] Shielding is increased by more cations per cage, smaller cage size, more waters per cage, or increased donation of electrons from the framework oxygen atoms to the unoccupied orbitals of Cs.[44, 45]

Ion Exchange and Selectivity of SNL-B. Ion exchange and selectivity experiments were performed to determine if: 1) SNL-B can exchange its Cs cations and 2) SNL-B demonstrates any selectivity for specific cations. In fact, greater than 90 atomic $\%$ of the Cs of SNL-B can be exchanged for $\mathrm{Na}$ or Sr by repeated contact with hot solutions containing an excess of the exchange cation. This exchange capacity is comparable to that of Cs/Si/Ti pharmacosiderite.[11] The ion exchanges of SNL-B take place without any framework distortion, as indicated by the X-ray diffraction spectra of ion exchanged SNLB. No peak shifts are observed, only relative peak intensity changes.

Additionally, SNL-B exhibits high selectivity for $\mathrm{Sr}$ with $\mathrm{K}_{\mathrm{d}}>100,000 \mathrm{ml} / \mathrm{g}$ (i.e. no $\mathrm{Sr}$ detected in solution after contact with SNL-B). On the other hand, a $\mathrm{K}_{\mathrm{d}}=19 \mathrm{ml} / \mathrm{g}$ was measured for adsorption of $\mathrm{Na}$ onto SNL-B. In these experiments, the selectivity behavior 
of the $\mathrm{Cs} / \mathrm{Si} / \mathrm{Ti}$ pharmacosiderite impurity phase needs to be taken into account. For comparable experiments, $\mathrm{K}_{\mathrm{d}}$ values for $\mathrm{Sr}$ and $\mathrm{Na}$ on Cs/Si/Ti pharmacosiderite of 1800 and $30 \mathrm{ml} / \mathrm{g}$ respectively, have been reported.[11] Given the $K_{d}$ for SNL-B is much greater than that reported for Cs/Si/Ti pharmacosiderite, it can be assumed the $\mathrm{Sr}$ selectively exhibited by our sample is due to the major SNL-B phase rather than the minor Cs/Si/Ti pharmacosiderite impurity phase. However, both SNL-B and Cs/Si/Ti pharmacosiderite can arguably contribute to the $\mathrm{Na} \mathrm{Kd}$ value. Therefore, the $\mathrm{K}_{\mathrm{d}}$ value of $19 \mathrm{ml} / \mathrm{g}$ of $\mathrm{Na}$ on SNL-B is a maximum distribution coefficient. In either case, SNL-B definitely shows extremely good selectivity for $\mathrm{Sr}$ and extremely poor selectivity for $\mathrm{Na}$. Ongoing selectivity experiments are underway to determine if this observed disparity in selectivity is due to the preference of SNL-B for divalent cations over monovalent cations.

Chemical durability of SNL-B. SNL-B is metastable relative to the other hydrothermally synthesized Cs/Si/Ti ternary oxides, SNL-A and Cs/Si/Ti pharmacosiderite. Alteration to one of these phase is observed as a result of extensive hydrothermal treatment of SNL-B. Note also, partial alteration to Cs/Si/Ti pharmacosiderite was also observed for the ron exchange experiments in which SNL-B was treated with hot $\left(80-90^{\circ} \mathrm{C}\right)$ aqueous solutions.

A standard PCT leach test was carried out to determine the leachability of Cs from SNLB. The leach rates are plotted in figure 6, based on a BET determined external surface area of $89 \mathrm{~m}^{2} / \mathrm{g}$. The leach rates for SNL-B are approximately 6 orders of magnitude higher than those observed for $\mathrm{Cs} / \mathrm{Si} / \mathrm{Ti}$-pharmacosiderite, which has a similar external surface area of $86 \mathrm{~m}^{2} / \mathrm{g}$. [8] Analysis of the post-leached samples by XRD reveals relative peak intensities of SNL-B are diminished, and broad peaks of Cs/Si/Tipharmacosiderite are apparent. Figure 7 shows TEM images of SNL-B before and after leach tests. The leached SNL-B has a "mottled" appearance and a fine precipitate is observable. consistent with high leach rates and a dissolution/reprecipitation texture.

From the synthesis precursor mixture described, SNL-B is the stable phase formed at 120 ${ }^{\circ} \mathrm{C}$ for up to 28 days of heating; at which time SNL-A $\left(\mathrm{Cs}_{2} \mathrm{TiSi}_{6} \mathrm{O}_{15}\right)$ is formed, which is 
extremely durable and stable.[16] Alternatively, a heating temperature of $170^{\circ} \mathrm{C}$ results in SNL-B after 3 - 4 days, and alteration to the condensed phase (SNL-A) occurs between 5 7 days. This transformation is shown in the $\mathrm{X}$-ray diffraction pattern in figure 8 , for $2.5,7$ and 10 days heating time at $170^{\circ} \mathrm{C}$.

Electron Irradiation Studies. Radiation stability of all Cs-Ti-Si-O- $\mathrm{H}_{2} \mathrm{O}$ phases synthesized in this study is important in order to assess the durability of the phases for ion exchange with radionuclides or radioactive waste form applications. Electron irradiation with in situ TEM studies have proven to be useful in simulating the effects of ionizing radiation damage caused by fission products.[46, 47] The results from our studies indicate that SNL-B behaves as traditional zeolites.[46, 47]

The amorphization dose due to electron irradiation of SNL-B was studied as a function of temperature. The electron dose on the sample was determined by:

$$
\text { Dose } \left.=i \times M^{2} \times t \text { (electrons } / \mathrm{cm}^{2}\right)
$$

where $i$ is the screen current density measured through an area where no sample is present to obscure the electron beam, $M$ is magnification of the microscope and $t$ is the time for the sample to achieve full amorphization. The irradiation-induced transformation from the crystalline-to-amorphous material is observed by the fading of the Bragg-diffraction spots in the electron diffraction pattern (figure 9). The dose for amorphization at room temperature is $2 \times 10^{20}$ electrons $/ \mathrm{cm}^{2}$. The temperature dependence of irradiation-induced amorphization is shown in figure 10. The dose needed for amorphization is constant up to $500{ }^{\circ} \mathrm{C}$, and then decreases sharply as a result of thermally-induced amorphization. This observation also agrees with differential thermal analysis (DTA) of SNL-B for which an exothermic phase change occurs at $550^{\circ} \mathrm{C}$. Analcime, an aluminosilicate zeolite was reported to exhibit similar response to electron irradiation upon heating, as a result of thermally induced structure collapse. $[46,47]$ 


\section{Summary and Conclusions}

In the course of our ongoing studies of ternary phases in the system Cs-Ti-Si-O- $\mathrm{H}_{2} \mathrm{O}$, we have produced $\mathrm{Cs}_{3} \mathrm{TiSi}_{3} \mathrm{O}_{9.5} \cdot 3 \mathrm{H}_{2} \mathrm{O}(\mathrm{SNL}-\mathrm{B})$ a novel molecular sieve ion exchanger. In addition to a $\mathrm{Cs} / \mathrm{Si} / \mathrm{Ti}$-pharmacosiderite analogue $\left(\mathrm{HCs}_{3} \mathrm{Ti}_{4} \mathrm{Si}_{3} \mathrm{O}_{16} \bullet 4 \mathrm{H}_{2} \mathrm{O}\right), \mathrm{SNL}-\mathrm{B}$ is the only other reported molecular sieve silicotitanate which has been synthesized with $C s$ as its charge balancing cation. Spectroscopic characterizations of SNL-B show a complex phase with multiple silicon coordination sites (2) and Cs cation exchange sites (2). SNL-B exhibits a very high leach rate for $\mathrm{Cs}$ as a result of its metastability. Additionally, SNL-B is not stable under electron irradiation; it behaves in a fashion similar to other zeolitic materials when exposed to electron irradiation. SNL-B also undergoes alteration to a condensed leach resistant $\mathrm{Cs} / \mathrm{Si} / \mathrm{Ti}$ phase, SNL-A that is the topic of forthcoming publication.[16] Ongoing work includes crystal growth experiments to obtain structural data on this unique phase. 


\section{Acknowledgements}

This work was supported by the U.S. DOE under contract DE-AC04-94AL85000 (Sandia National Laboratories).

All authors thank the DOE Environmental Management Science Program (EMSP) for funding for this work under separate grants for University of Michigan and Sandia National Laboratories (EMSP grant DE-FG07-97ER45652 at University of Michigan, project \#27601 at Sandia National Laboratories).

We thank Dr. Todd Alam at Sandia National Laboratories for the NMR spectroscopy experiments and Steve Thoma for the surface area analyses.

\section{References}

Sandia is a multiprogram laboratory operated by Sandia Corporation, a Lockheed Martin Company, for the United States Department of Energy under contract DE-AC04-94AL85000.

[1] R. G. Anthony, C. V. Phillip, R. G. Dosch, Waste Management 13 (1993) 503.

[2] R. G. Anthony, R. G. Dosch, D. Gu, C. V. Philip, Ind. Eng. Chem. Res. 33 (1994) 2702 .

[3] D. M. Poojary, R. A. Cahill, A. Clearfield, Chem. Mater. 6 (1994) 2364.

[4] T. M. Nenoff, S. G. Thoma, J. L. Krumhansl, "The Stability and Selectivity of

TAM5: A Silicotitanate Molecular Sieve for Radwaste Clean-up", SAND96-2580, Sandia National Laboratories, Albuquerque, November, 1996.

[5] T. M. Nenoff, J. L. Krumhansl, "The Structure of TAM5: A Silicotitanate Molecular Sieve for Radwaste Clean-up", SAND96-2578, Sandia National Laboratories, Albuquerque, November 1996.

[6] Y. Su, M. L. Balmer, L. Wang, B. C. Bunker, T. M. Nenoff, M. Nyman, A. Navrotsky, MRS Conference Proceedings (Boston), "Evaluation of Thermally Converted Silicotitanate Waste Forms (1998).

[7] Y. Su, M. L. Balmer, B. C. Bunker, MRS Conference Proceedings (Boston), "Evaluation of Cesium Silicotitanates as an Alternative Waste Form", p. 457 (1997).

[8] M. Nyman, T. M. Nenoff, Y. Su, M. L. Balmer, A. Navrotsky, H. Xu, MRS Conference Proceedings (Boston), "New Crystalline Silicotitanate (CST) Waste Forms: Hydrothermal Synthesis and Characterization of $\mathrm{Cs}-\mathrm{Si}-\mathrm{Ti}-\mathrm{O}$ Phases (1998). 
[9] M. L. Balmer, Y. Su, I. E. Grey, A. Santoro, R. S. Roth, Q. Huang, N. Hess, B. C. . Bunker, MRS Conference Proceedings, "The Structure and Properties of Two New Silicotitanate Zeolites", p. 449 (1997).

[10] M. L. Balmer, Q. Huang, W. Wong-Ng, R. S. Roth, A. Santoro, J. Solid State Chem. 130 (1997) 97.

[11] E. A. Behrens, D. M. Poojary, A. Clearfield, Chem. Mater. 8 (1996) 1236.

[12] E. A. Behrens, A. Clearfield, Microporous Mater. 11 (1997) 65.

[13] W. T. A. Harrison, T. E. Gier, G. D. Stucky, Zeolites 15 (1995) 408.

[14] D. E. McCready, M. L. Balmer, K. D. Keefer, Powder Diffr. 12 (1997) 40.

[15] I. E. Grey, R. S. Roth, M. L. Balmer, J. Solid State Chem. 131 (1997) 38.

[16] M. Nyman, F. Bonhomme, D. Teter, T. M. Nenoff, R. C. Ewing, L. M. Wang, B. X. Gu, Chem. Mater. submitted (2000).

[17] X. Wang, X. Guo, Catal. Today 51 (1999) 177.

[18] C. B. Dartt, M. E. Davis, Appl. Catal. A 143 (1996) 53.

[19] J. S. Reddy, R. Kumar, P. Ratnasamy, Appl. Catal. 58 (1990) L1.

[20] D. P. Serrano, H. X. Li, M. E. Davis, J. Chem. Soc., Chem. Commun. (1992) 745.

[21] B. Kraushaar-Czernezki, J. H. C. v. Hooff, Catal. Lett. 2 (1989) 43.

[22] S. M. Kuznicki, Patent \# 4,853,202, U.S.A. 1989.

[23] X. Liu, J. K. Thomas, J. Chem. Soc., Chem. Commun. (1996) 1435.

[24] S. M. Kuznicki, Patent \# 4,938,939, U.S.A. 1990.

[25] T. K. Das, A. J. Chandwadkar, S. Sivasanker, J. Chem. Soc., Chem. Commun. (1996) 1105.

[26] D. M. Chapman, A. L. Roe, Zeolites 10 (1990) 730.

[27] M. S. Dadachov, J. Rocha, A. Ferreira, Z. Lin, M. W. Anderson, J. Chem. Soc., Chem. Commun. (1997) 2371.

[28] S. Merlino, M. Pasero, A. Khomyakov, Zeit. Kristallog. 193 (1990) 137.

[29] A. Clearfield, A. I. Bortun, L. N. Bortun, R. A. Cahill, Solvent Extr. Ion Exch. 15 (1997) 285.

[30] Y. Liu, H. Du, F. Zhou, W. Pang, J. Chem. Soc., Chem. Commun. (1997) 1467. 
[31] G. Ferraris, G. Ivaldi, A. P. Khomyakov, S. V. Soboleva, E. Belluso, A. Pavese, European J. Miner. 8 (1996) 241.

[32] M. A. Roberts, G. Sankar, J. M. Thomas, R. H. Jones, H. Du, J. Chen, W. Pang, R. Su, Nature 381 (1996) 401.

[33] H. Du, M. Fang, J. Chen, W. Pang, J. Mater. Chem. 6 (1996) 1827.

[34] H. Xu, A. Navrotsky, M. Nyman, T. M. Nenoff, M. L. Balmer, Y. Su, J. Mater. Chem. in press (2000).

[35] A. Boultif, D. Louer, J. Appl. Crystallography 24 (1991) 987.

[36] M. G. Mesko, D. E. Day, J. Nucl. Mater. 273 (1999) 27.

[37] H. Li, M. Tomozawa, J. non-Crystalline Sol. 195 (1996) 188.

[38] JCPDS Database, Swarthmore 1992.

[39] H. Du, F. Zhou, W. Pang, Y. Yue, Microporous Mater. 7 (1996) 73.

[40] P. Launer, Infrared analysis of organosilicon compounds, Petrarch systems 1987.

[41] M. L. Balmer, B. C. Bunker, L. Q. Wang, C. H. F. Peden, Y. Su, J. Phys. Chem. B 101 (1997) 9170.

[42] A. Labouriau, T. J. Higley, W. L. Earl, J. Phys. Chem. 102 (1998) 2897.

[43] P. J. Dirken, M. E. Smith, H. J. Whitfield, J. Phys. Chem. 99 (1995) 395.

[44] T. Tokuhiro, M. Mattingly, L. E. Iton, M. K. Ahn, J. Phys. Chem. 93 (1989) 5584.

[45] F. Yagi, N. Kanuka, H. Tsuji, S. Nakata, H. Kita, H. Hattori, Microporous Mater. 9 (1997) 229.

[46] L. M. Wang, S. X. Wang, R. C. Ewing, 9th Annual International High-Level Radioactive Waste Management Conference (Las Vegas, NV), "Radiation Effects in Zeolites: Relevance to Near-Field Contamination", p. 772 (1997).

[47] B. X. Gu, L. M. Wang, R. C. Ewing, J. Nucl. Mater. 278 (2000) 64. 
Table I. Calculated and Observed Peaks of SNL-B

\begin{tabular}{lllll}
\hline $\mathbf{h}$ & $\mathbf{k}$ & $\mathbf{l}$ & $\mathbf{d}_{\text {obs }}(\AA)$ & $\mathbf{d}_{\text {caic }}(\AA)$ \\
\hline $\mathbf{l}$ & 0 & 0 & 10.80 & 10.83 \\
0 & 1 & 0 & 7.42 & 7.43 \\
2 & 0 & 0 & 5.41 & 5.42 \\
0 & 1 & 1 & 5.14 & 5.14 \\
2 & 1 & 0 & 4.38 & 4.38 \\
2 & 1 & 1 & 3.73 & 3.73 \\
0 & 0 & 2 & 3.56 & 3.56 \\
1 & 2 & 0 & 3.52 & 3.52 \\
0 & 1 & 2 & 3.21 & 3.21 \\
2 & 2 & 0 & 3.07 & 3.07 \\
2 & 0 & 2 & 2.98 & 2.98 \\
0 & 2 & 2 & 2.57 & 2.57 \\
\hline
\end{tabular}




\section{Figure Captions}

Figure 1. Powder X-ray diffraction patterns of SNL-B (top) and the major peak positions indexed (bottom).

Figure 2. Scanning electron micrographs showing the radiating, blade-like habit of SNLB crystallites.

Figure 3. Thermogravimetric analysis of SNL-B showing desorption and subsequent adsorption cycle.

Figure 4. Infrared spectrum of SNL-B.

Figure 5. Solid-state MAS NMR spectra of SNL-B: a) ${ }^{29} \mathrm{Si}$ spectrum (top) b) ${ }^{133} \mathrm{Cs}$ spectrum (bottom).

Figure 6. a) PCT leach rates of Cs from SNL-B as a function of time $(0.1 \mathrm{~g}$ sample heated in $10 \mathrm{ml} \mathrm{H}_{2} \mathrm{O}$ at $90^{\circ} \mathrm{C}$ ).

Figure 7. a) TEM bright field image of SNL-B, prior to leaching. b) TEM bright field image of SNL-B, post-leaching.

Figure 8. X-ray diffraction spectra showing hydrothermal transformation of SNL-B to SNL-A, Cs-silicotitanate condensed phase.[16]

Figure 9. Sequence of selected-area diffraction patterns of SNL-B during $200 \mathrm{KeV}$ electron beam irradiation: A. nonirradiated. B. intermediate state, $1.2 \times 10^{20}$ electrons $/ \mathrm{cm}^{2}$ irradiation dose. C. fully amorphized, $2.0 \times 10^{20}$ electrons $/ \mathrm{cm}^{2}$ irradiation dose.

Figure 10. Temperature dependence of amorphization dose for SNL-B under $200 \mathrm{KeV}$ electron irradiation. 


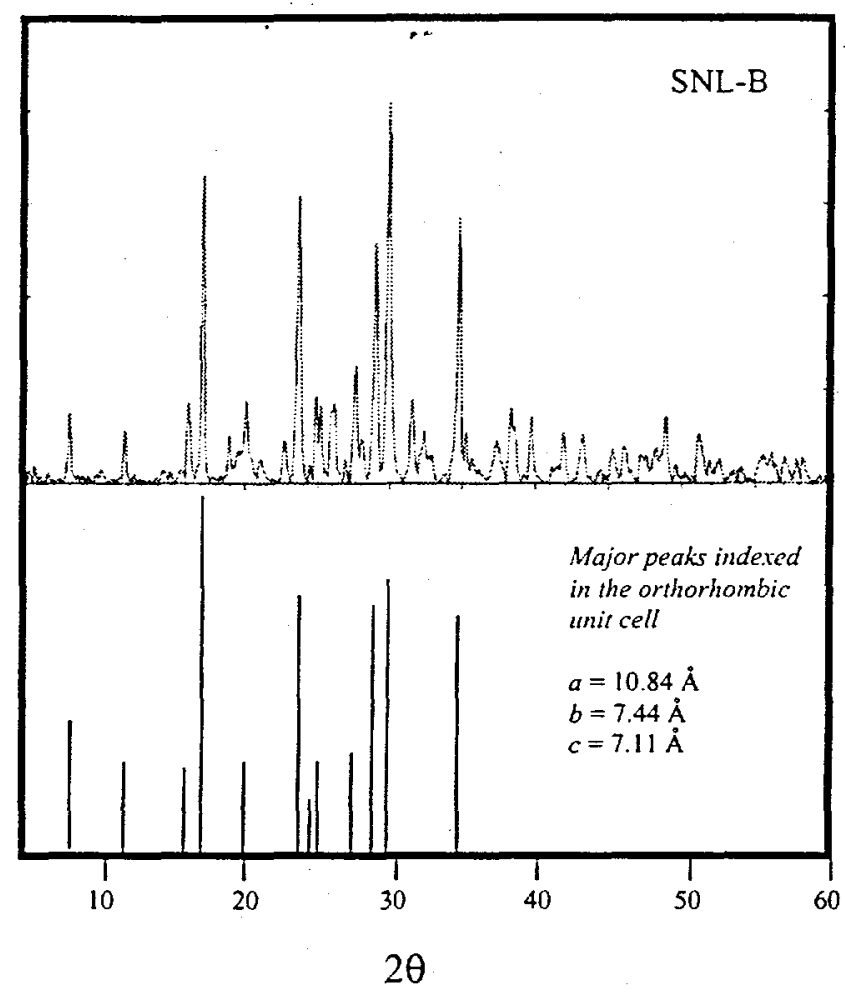




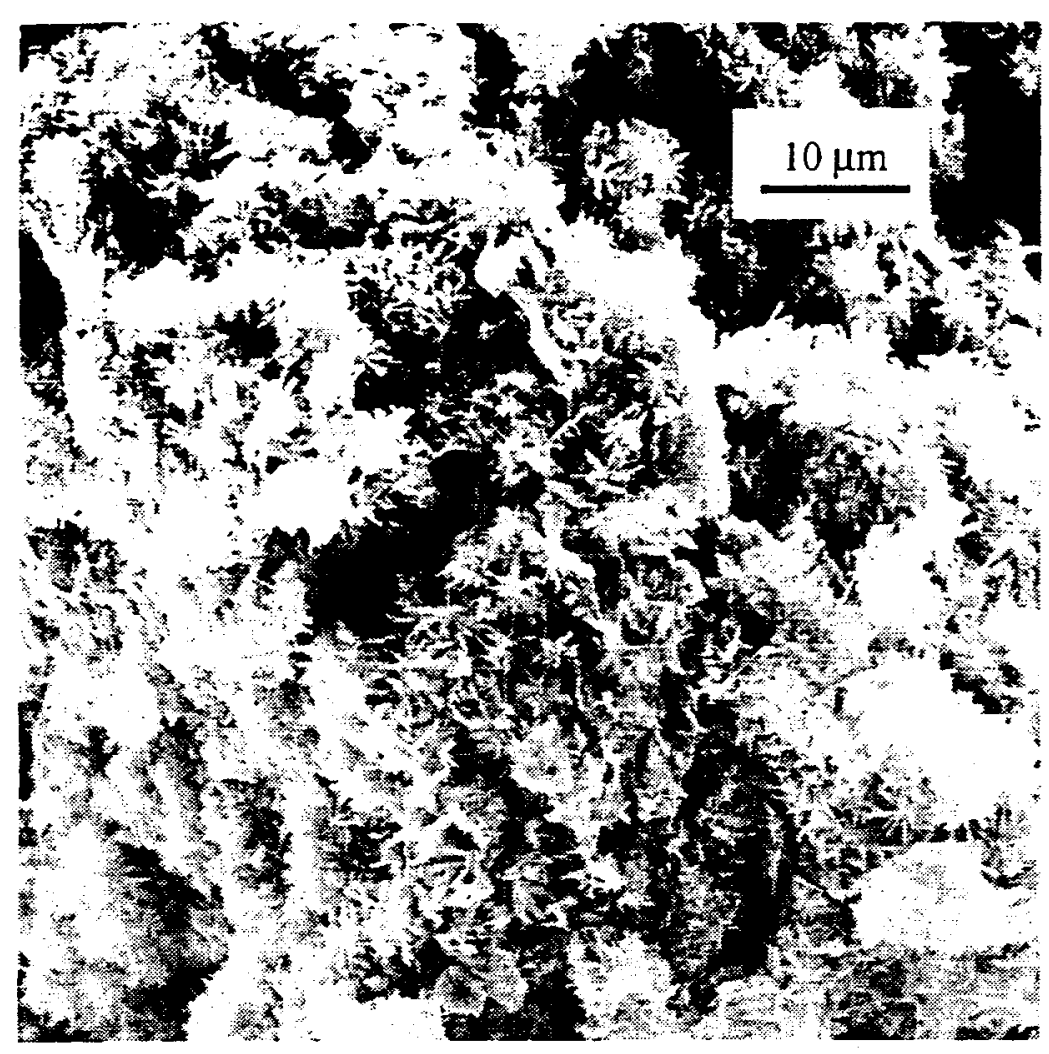




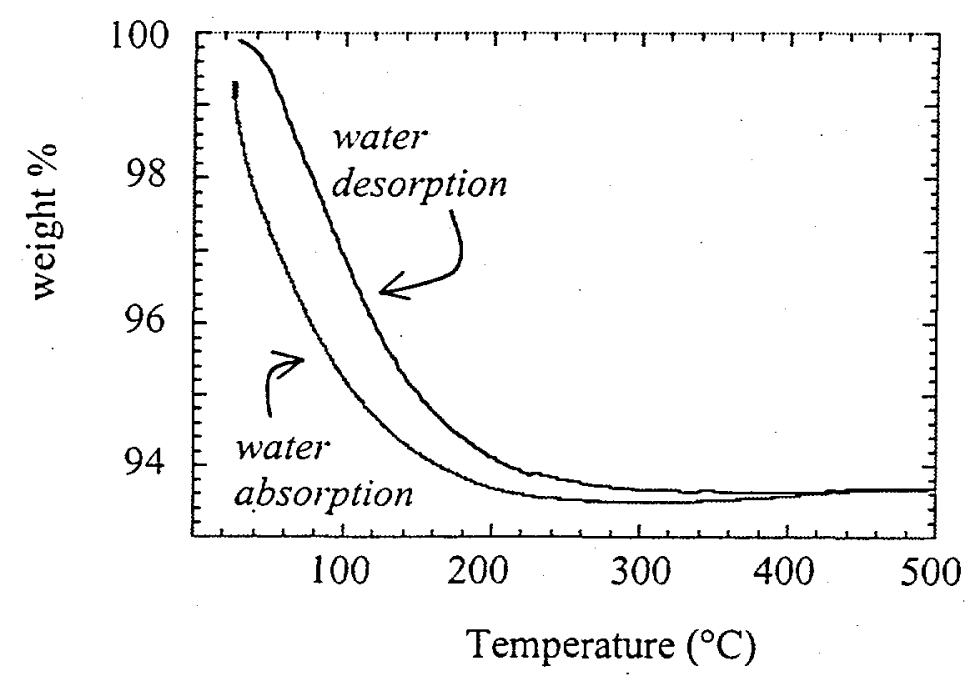




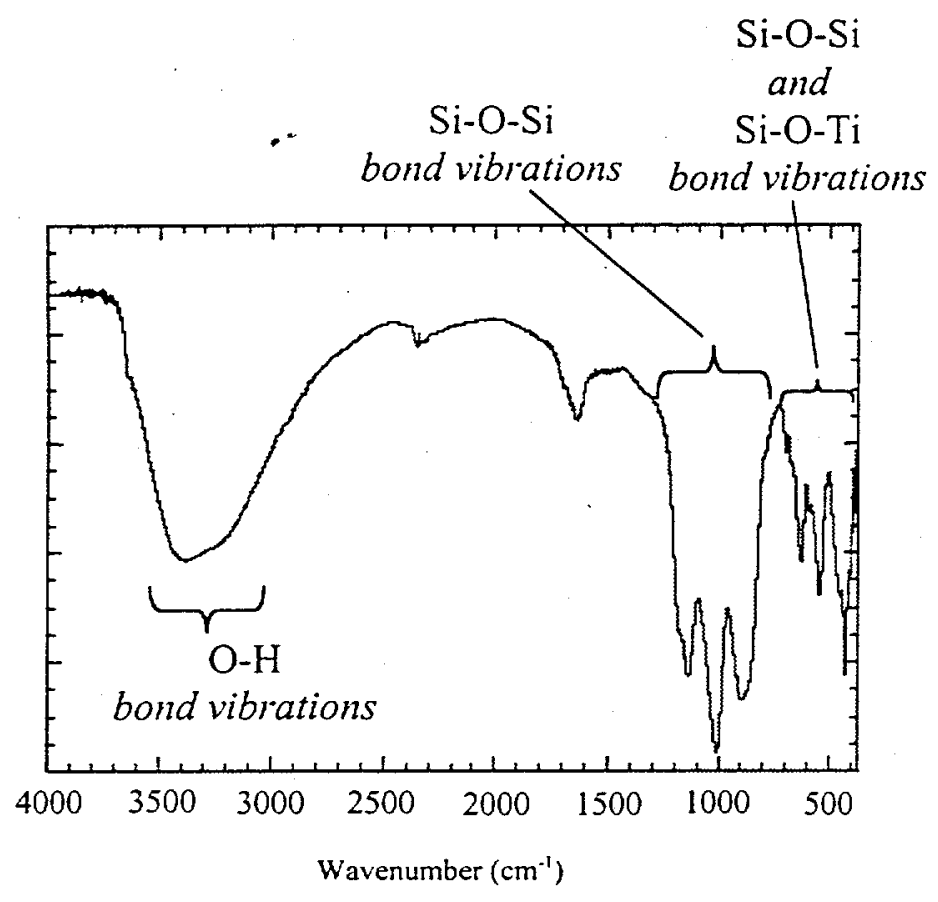



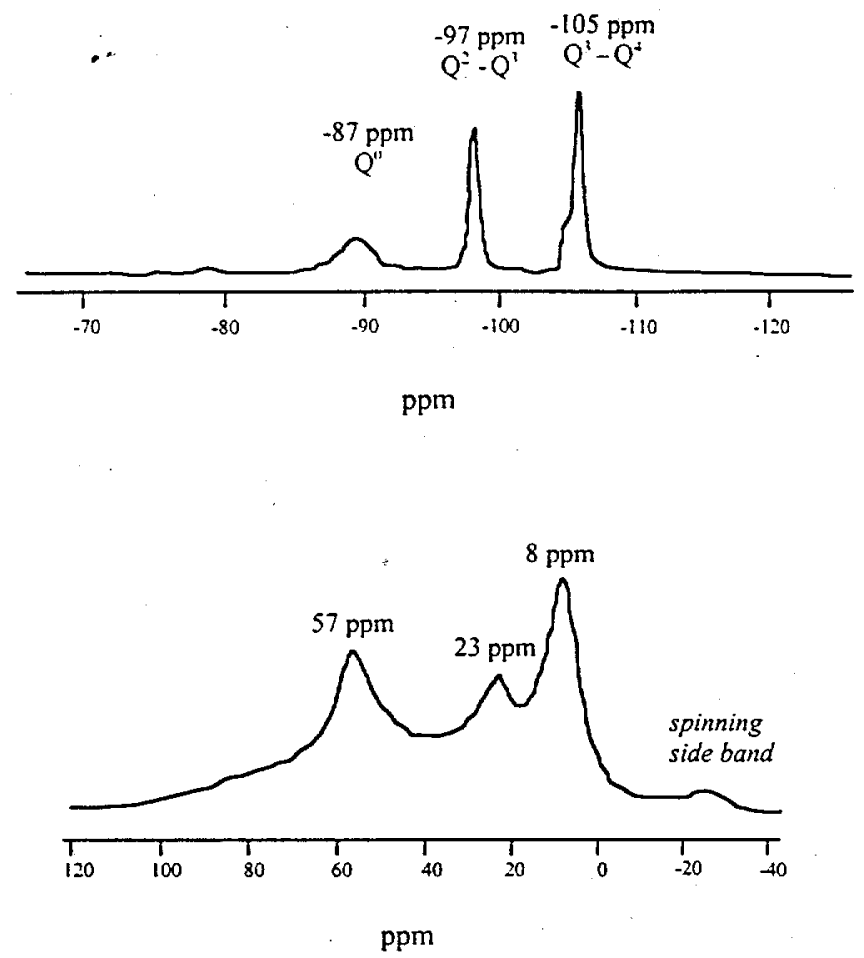


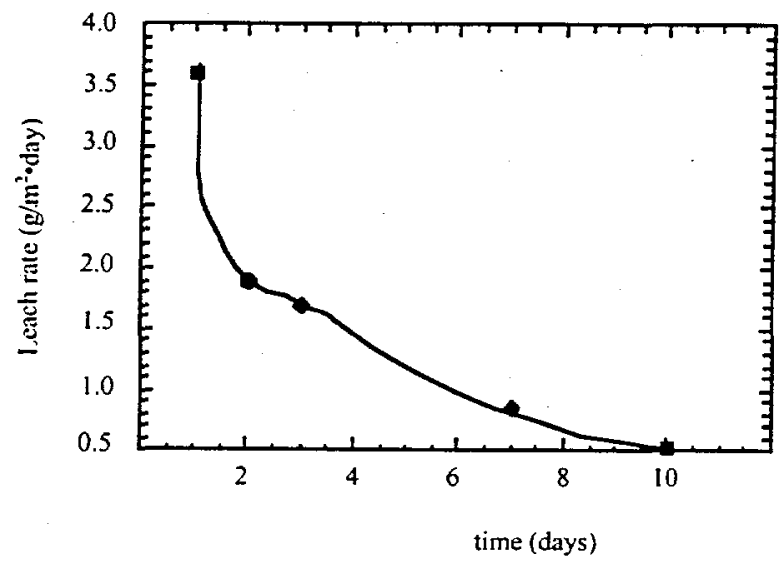




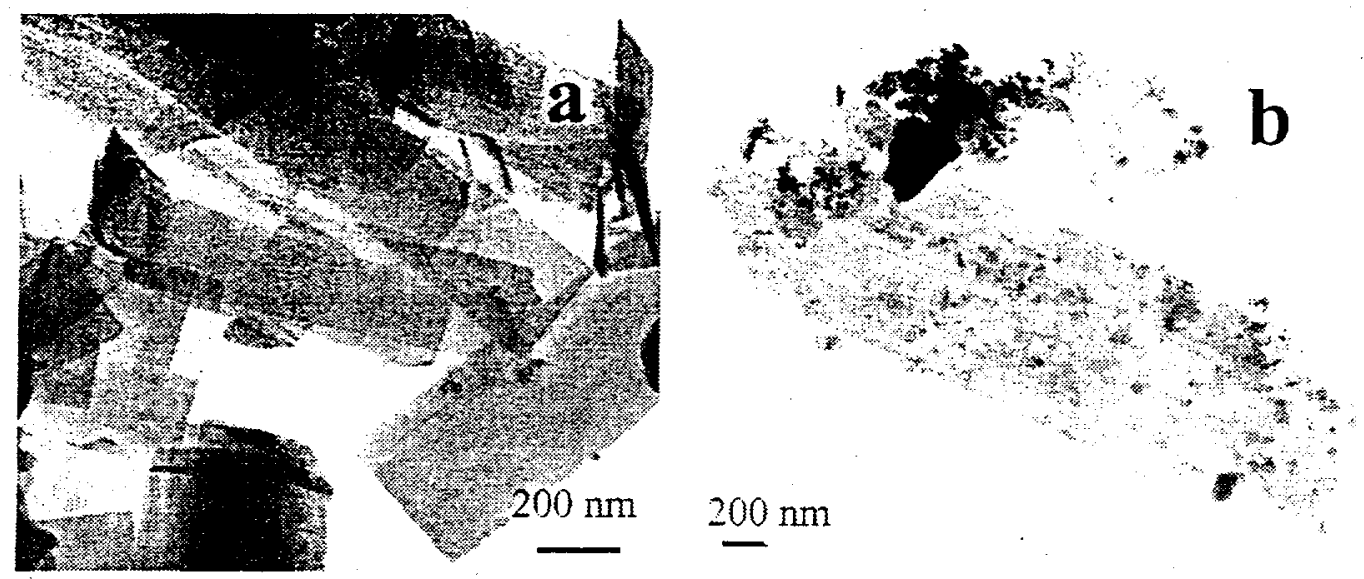




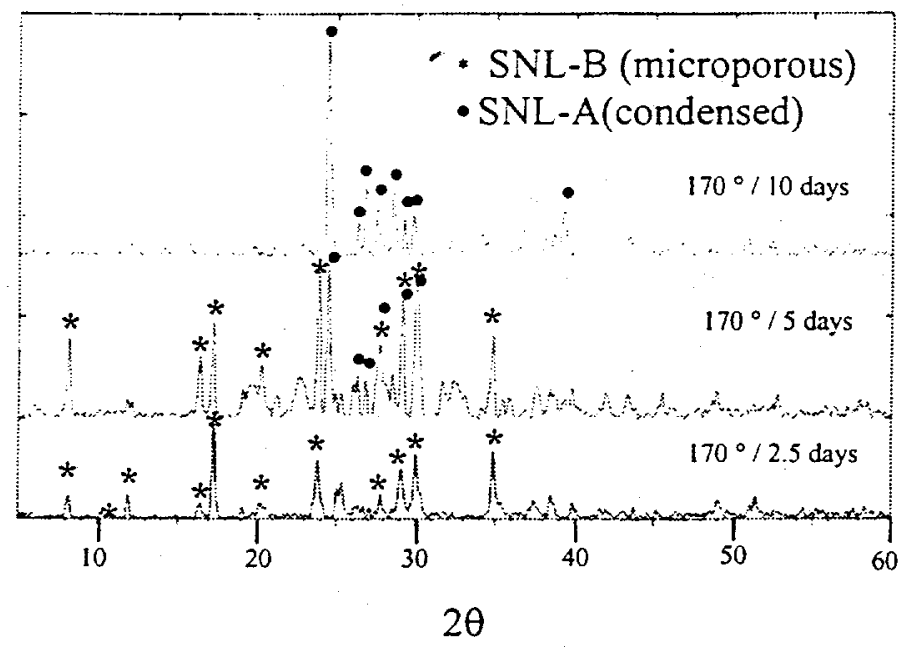



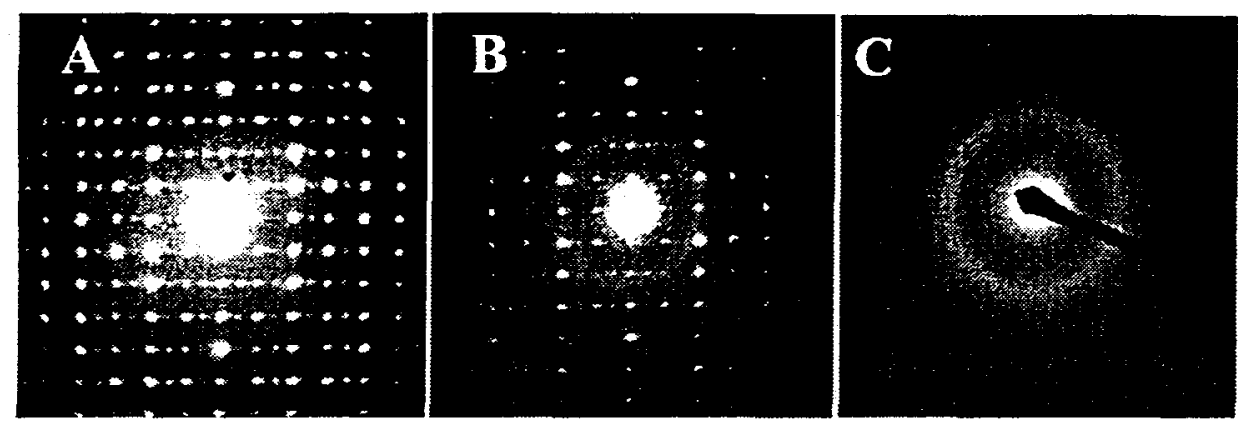


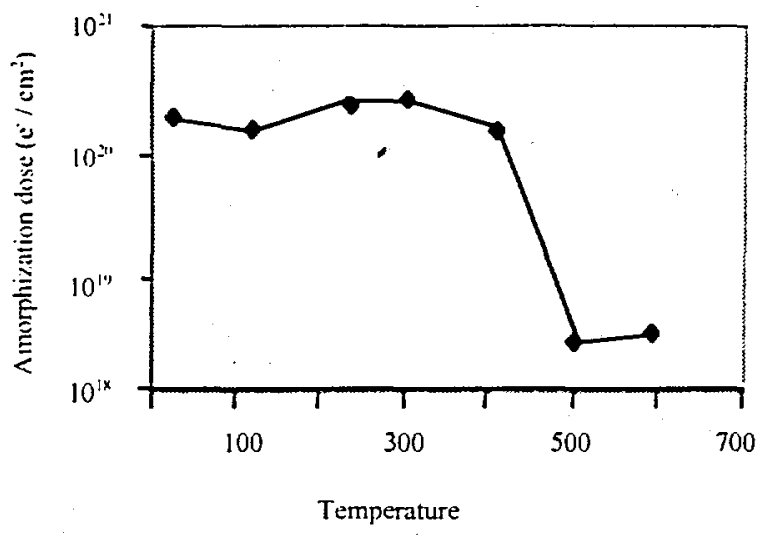

